\title{
Tudo que é humano ressoa no coração da fé: discernir a missão universitária à luz dos sinais dos tempos
}

\author{
All that is human reverberates within the heart of faith: discerning the \\ university's mission in the light of the signs of the times
}

Pedro Rubens*

\begin{abstract}
Resumo
O Concílio Vaticano II evidenciou a importância de discernir os "sinais dos tempos" para definir a missão cristã no seio do mundo e para exercer o próprio labor teológico. Ao celebrarmos, em 2015, o cinquentenário do concílio Vaticano II e da declaração Gravissimum educationis, bem como o vigésimo quinto aniversário da Constituição Apostólica Ex corde Ecclesiae, uma tarefa importante recai sobre a teologia fundamental: como discernir e redefinir a missão das universidades católicas no seio das novas situações humanas? Na presente reflexão, a título de exercício, proponho três passos para um discernimento teológico, que só pode ser feito por cada comunidade acadêmica: primeiro, identificar alguns grandes apelos na realidade paradoxal que caracteriza o tempo atual; segundo, redefinir a missão própria de uma universidade católica à luz de uma releitura da constituição apostólica Ex corde Ecclesiae; terceiro, a partir da perspectiva lançada pelo concílio, reafirmar a centralidade do Evangelho, fonte da fé e da teologia, como critério último de todo discernimento. E, à guisa de conclusão aberta, destaco alguns pontos fundamentais para a missão de uma universidade católica na contemporaneidade.
\end{abstract}

Palavras-chave: Vaticano II; Ex corde Ecclesiae; missão das universidades católicas.

\begin{abstract}
The Second Vatican Council showed the importance of discerning the "signs of the times" to define the Christian mission in the world, and to exercise its own theological work. As we celebrate, in 2015, with the 50th anniversary of the Second Vatican Council and of the Gravissimum educationis declaration, as well as the 25th anniversary of the Ex corde Ecclesiae Apostolic Constitution, an important task falls upon fundamental theology: how to discern and redefine the mission of Catholic universities at the core of new human situations? In the present reflection, as a hypothesis, I propose three steps for theological discernment, which can only be carried out in each academic community. First, to identify some major callings in the paradoxical reality which characterizes current times. Second, to redefine the mission of a Catholic university in light of a reinterpretation of the Ex corde Ecclesiae apostolic constitution. Third, to reaffirm the centrality of the Gospel which is the source of faith and theology, as the ultimate criterion of all discernimentas. Finally, as an open conclusion, we highlight some fundamental points for the mission of a Catholic universities in contemporaneity.
\end{abstract}

Keywords: Second Vatican Council; Ex corde Ecclesiae; mission of Catholic universities.

\footnotetext{
Artigo recebido em 18 de setembro de 2015 e aprovado em 15 de dezembro de 2015.

* Doutor em Teologia pelo Centre Sèvres, Facultés Jésuites de Paris e reitor da Universidade Católica de Pernambuco. País de origem: Brasil. E mail: pedro_rubens@hotmail.com
} 


\section{Introdução}

$\mathrm{Na}$ igreja e teologia pós-Vaticano II, tornou-se quase banal falar de "sinais dos tempos" para identificar os apelos do tempo presente e definir os termos da missão eclesial. E, cinco décadas depois, efetivamente, não se pode buscar as "razões de nossa esperança” (1 Pd 3,15s), função primeira da teologia fundamental e de toda teologia (METZ, 1999)ํㅗㅇ , sem discernir os apelos de Deus presentes nas mais diversas situações humanas. No entanto, o exercício parece tão mais difícil quão necessário 50 anos depois do encerramento do concílio, seja pela maior complexidade do mundo, seja pela pluralidade irredutível de concepções, sobretudo no meio universitário.

Nesse contexto, percebe-se uma situação extremamente paradoxal: um eclipse do cristianismo nas sociedades ocidentais, que se autoproclamam laicas e pós-cristãs (e o meio universitário brasileiro é o mais laico e secularizado do país!), mas, ao mesmo tempo, assiste-se ao ressurgimento do religioso sob todas as suas formas, no seio da vida contemporânea. Depois de certo tempo, há sinais de "ressurgimento do religioso" (LIBANIO, 2002)² e de "recomposição do cristianismo" (HERVIEU-LEGER, 1987, 1999); mas, caberia interrogar sobre o que significa "retorno" em um país como o Brasil, no qual o religioso esteve sempre presente, não sem ambiguidades, com rupturas e continuidades (TEIXEIRA; MENEZES, 2006) ou sobre quais os sinais de nosso tempo que indicam alguma real novidade.

Seja como for, o discernimento permanece como uma tarefa fundamental da teologia. Na presente reflexão, portanto, proponho um exercício de discernimento em três atos: primeiro, para identificar alguns grandes apelos no seio da realidade paradoxal do tempo atual; segundo, redefinir a missão própria de uma

\footnotetext{
${ }^{1}$ A "apologia da esperança" é uma característica comum de toda teologia autenticamente cristã e, nesse sentido, ela é "tão antiga quanto a história da fé e de suas contestações" (METZ, 1999, p. 30), segundo a tradição da epístola de Pedro (1 Pd 3,15s): "estai sempre prontos a dar razões da vossa esperança a todo aquele que dela vos pedir contas".

${ }^{2}$ Entre uma ampla bibliografia, parece significativa a obra de Marcel Gauchet (2004), Un monde désenchanté?, na qual o autor responde às objeções, interpelações e esclarecimentos sobre seu livro intitulado Désenchantement du monde (GAUCHET, 1985).
} 
universidade católica à luz de uma releitura da constituição apostólica Ex corde Ecclesiae; terceiro, à guisa de conclusão aberta, destacaremos alguns desafios de uma missão universitária como apologia de uma esperança no seio da contemporaneidade.

\section{Os sinais do tempo presente à luz da fé}

Nascida do coração da Igreja - Ex corde Ecclesiae -, a universidade católica não poderia definir sua identidade e missão sem identificar os desafios do tempo presente e sem discernir, com a ajuda dos diversos saberes, os apelos de Deus em tudo o que é humano, seguindo os passos indicados pelo concílio Vaticano II:

Movido pela fé, conduzido pelo Espírito do Senhor que enche o orbe da terra, o Povo de Deus esforça-se por discernir nos acontecimentos, nas exigências e nas aspirações de nossos tempos, em que participa com os outros homens, quais sejam os sinais verdadeiros da presença ou dos desígnios de Deus. A fé, com efeito, esclarece todas as coisas com luz nova. Manifesta o plano divino sobre a vocação integral do homem. E por isso orienta a mente para soluções plenamente humanas (CONCÍLIO VATICANO, 2., Gaudium et Spes, 2009, 11 § 1, destaque nosso).

A missão da universidade no mundo dos saberes é indissociável da missão universal da Igreja e, por isso mesmo, é solidária com todas as situações humanas, diante das quais se exercita um discernimento cordial dos sinais, pois "não se encontra nada verdadeiramente humano que não lhes [dos discípulos de Cristo] ressoe no coração” (CONCÍLIO VATICANO, 2., Gaudium et Spes, 2009, 1).

Para uma aproximação hermenêutica da realidade, postulo três indicadores principais do espírito do tempo presente: primeiramente, a quebra de paradigma com o pensamento que se diz pós-moderno; segundo, a consolidação da sociedade do conhecimento, não sem contradições; e, terceiro, o fenômeno da globalização e/ou mundialização, pleno de ambiguidades. 


\section{A quebra do paradigma moderno}

Mais que entrar no debate conceitual, importa aqui perceber as características que indicam o que se tenta denominar como "pós-modernidade", distinguindo algumas diferenças em relação à modernidade. Nossa hipótese de trabalho considera, portanto, o tempo presente a partir de um "duplo desmoronamento" na cultura ocidental: o fim da cristandade e, depois, o desencanto com a modernidade (MENDOZA-ÁLVAREZ, 2011)3. A modernidade anunciou o fim da minoridade e prometeu uma emancipação do ser humano em contraposição à cristandade. Mas, depois de um apogeu surpreendente, evidenciaram-se os sinais de declínio, sem que isso represente um retorno à mentalidade pré-moderna. No âmago deste "duplo fracasso", os mestres da desconstrução vão tornando patente o paradigma pós-moderno, ainda pouco definido ou bastante polêmico. Mas, em todo caso, não podemos ficar surdos ao grito das vítimas desse sistema moderno e nem cegos ao desmascaramento das mazelas da modernidade em sua pretensão totalizante da realidade (MENDOZAÁLVAREZ, 2011)4.

Surpreendentemente, na própria contemporaneidade, identificamos também algumas lógicas e valores da modernidade tardia, além de resquícios prémodernos e barrocos, notadamente em uma república como o Brasil e, sobretudo, depois da liberdade religiosa proposta por Vaticano II e, ao mesmo tempo, dos processos de avanços e recuos de uma jovem democracia. No cenário atual, assistimos ao ressurgimento do religioso, reeditando formas próprias da cristandade, além de resgatar expressões arcaicas e primitivas, quando não intolerantes. No entanto, o meio universitário brasileiro ainda guarda muitas “suspeitas” em relação à religião em geral e à Igreja católica em particular; mas, ao mesmo tempo, a igreja católica goza de respeito e credibilidade, entre as

\footnotetext{
${ }^{3}$ Tendo feito o Prefácio da obra, indico o conjunto da reflexão ("ensaio") de teologia fundamental como um todo, partindo dessa leitura da pós-modernidade.

${ }^{4}$ A reflexão do jovem teólogo mexicano contempla a perspectiva das vítimas de uma violência sistêmica, dialogando com a pósmodernidade e com o pensamento de René Girard.
} 
instituições brasileiras, sobretudo depois de atitudes firmes e corajosas depois do concílio Vaticano II, sobretudo nos tempos da ditadura militar: a abertura da igreja pós-conciliar universal coincidiu, no Brasil (e em outros países da América latina), com o "fechamento" político (golpe militar de 1964 a 1985).

Essa situação paradoxal - sentimento religioso crescente e meio universitário laico e secularizado - representa um desafio ao pensamento e à atuação das universidades católicas; mas, também oferece oportunidades novas para aprofundarmos o diálogo entre fé e razão na perspectiva de uma nova relação entre religião e cultura, humanidade e transcendência, Igreja e sociedade.

\section{Sociedade do Conhecimento em questão}

A sociedade moderna alcançou, ao longo do século XX, um alto grau de conhecimento, em princípio, capaz de resolver os problemas mais graves da humanidade. Mas o limiar da modernidade revela também sinais de seu declínio, mostrando a alta complexidade da própria sociedade. O conhecimento científico e sua aplicação tecnológica transformaram-se em uma arma poderosa para a sociedade e, ao mesmo tempo, em uma ameaça para a própria humanidade. Esse cenário provoca dúvidas e incertezas em relação ao sentido da vida e ao futuro da humanidade, suscitando novos paradoxos: atinge-se uma consciência da complexidade da sociedade e da própria humanidade, em suas dimensões irredutíveis e, ao mesmo tempo, reafirma-se a importância da responsabilidade humana ao lado de sua extrema fragilidade e impotência (pensamento "frágil”) diante de tal complexidade (sociedade complexa) (MORIN, 2000).

Nesse contexto, as universidades estão desafiadas a trabalhar o "remembramento dos conhecimentos" oriundos das "ciências naturais" (a fim de situar a condição humana no mundo) e das "ciências humanas" (para colocar em evidência a multidimensionalidade e a complexidade humanas), bem como 
integrar a "contribuição das humanidades" (inclusive a literatura, a poesia, as artes etc.) (MORIN, 2000, p. 48).

No século XXI, precisamos, enfim, superar a visão unilateral que define o ser humano pela racionalidade (Homo sapiens), pela técnica (Homo faber), pelas atividades utilitárias (Homo economicus), pelas necessidades obrigatórias (Homo prosaicus). O ser humano é complexo: ele é, ao mesmo tempo, sapiens e demens, faber e ludens, empiricus e imaginarius, economicus e consumans, prosaicus e poeticus (MORIN, 2000, p. 58).

Essa realidade complexa, no entanto, contém também sinais de esperança. No seio da própria sociedade do conhecimento, emerge uma nova consciência (socioambiental, direitos humanos, etc.) e a exigência de um conhecimento pertinente, capaz de apreender os problemas globais para neles inserir os parciais e os locais. Para essa articulação, é preciso compreender a situação em seu contexto, estabelecer relações entre o todo e as partes, reconhecer o caráter multidimensional da realidade e, enfim, assumir a complexidade de uma realidade que torna inseparáveis seus diversos aspectos: econômico, político, sociológico, psicológico, afetivo e espiritual (MORIN, 2000, p. 36-39)5. Tal situação contextual é uma grande oportunidade para as universidades católicas, seja para "reinventar" o sentido da Universitas magistrorum et scholarium ${ }^{6}$, seja para continuar propondo a formação humana integral, na qual "a qualidade acadêmica visa à excelência humana"7.

\section{Globalização sem limites, mundialização sem fronteiras}

A globalização e a mundialização são fenômenos incontestáveis e atingem todos os recantos do planeta, produzindo uma transformação das estruturas

\footnotetext{
${ }^{5}$ Embora de forma vaga e genérica, não deixa de ser interessante que o autor tenha indicado a dimensão espiritual em sua perspectiva.

${ }^{6}$ Cf. Carta do Papa Alexandre IV à Universidade de Paris, em 1255. (ALEXANDRE IV, 1255, apud JOÃO PAULO II, 1980, n. 1).

${ }^{7}$ Lema da Universidade Católica de Pernambuco, inspirado na Conferência de P. Hans Kolvenbach, Geral da Companhia de Jesus, proferida na Universidade de Santa Clara, EUA, em 6 de outubro de 2000.
} 
sociopolíticas, das relações econômicas e do universo de valores. Como tudo o que é histórico, muitas interpretações são possíveis, sobretudo em razão de sua complexidade. O uso indistinto desses dois termos - globalização e mundialização - tornou-se comum, mas prefiro fazer uma diferença para melhor percebermos a ambivalência do fenômeno. Nesse passo, quando falamos de globalização, referimo-nos especificamente ao estado atual do capitalismo internacional, com implicações econômicas, políticas e sociais; o termo mundialização refere-se, sobretudo, à ampliação das possibilidades de comunicação e ao encontro entre mundos diferentes, dos espaços geográficos às correntes ideológicas e culturais, com seus valores agregados.

Assim, delineiam-se dois grandes paradoxos do tempo presente, com seus sinais de risco e esperança. Primeiro, no horizonte da globalização: a possibilidade de resolver os grandes problemas da humanidade, com os recursos da ciência e da tecnologia, mas, praticamente, condicionada à concentração desses meios em alguns grupos e países, provocando um poder sem limites e/ou novas formas de exclusão, inclusive algumas de maneira radical e internacional, como atesta o problema de tantos migrantes "sans papier" ou, em linguagem brasileira, "sem lenço nem documento". Segundo paradoxo: no paradigma da mundialização, constata-se a multiplicação das condições e possibilidades de comunicação e, ao mesmo tempo, o aumento de incompreensão entre as pessoas e a multiplicação das formas de intolerância e de violência, tanto entre indivíduos quanto entre países, por motivos sociais, políticos e até religiosos, baseados em fundamentalismos de toda sorte. A verdadeira globalização, no entanto, deveria estar a serviço do gênero humano e da preservação de seu habitat (meio ambiente), da nossa "casa comum" (FRANCISCO, 2015), dentro de uma lógica da "coexistência” (CIRNE, 2013), portanto, dentro de uma perspectiva socioambiental. Na mesma linha, a mundialização atingiria seu pleno sentido se gerasse uma maior comunicação e solidariedade da humanidade inteira. 


\section{Uma referência da Tradição: Ex corde ecclesiae}

No passo precedente, ao indicar alguns aspectos dos tempos contemporâneos, em vista de um discernimento, não explicitamos a tradição da Igreja nem elementos essenciais do patrimônio espiritual do cristianismo. Resta, agora, definir a missão das universidades católicas, a partir de uma releitura da constituição apostólica Ex Corde Ecclesiae (ECE) (JOÃO PAULO II, 1980).

Depois da Constituição Apostólica Sapientia Cristiana (1979), escrita para as "universidades e faculdades eclesiásticas", o então Papa João Paulo II percebeu a necessidade de escrever outra Constituição Apostólica, desta feita específica para as universidades católicas, como uma "carta magna" (JOÃO PAULO II, 1980, n. 8). Assim, em 1990, surgiu a Ex Corde Ecclesiae, documento que nos servirá de "referência" (JOÃO PAULO II, 1980, n. 8) na reflexão da missão das universidades católicas e da pastoral universitária no seio da cultura contemporânea.

Enquanto a primeira parte do documento trata da "identidade e missão" de forma mais inspiradora (baseadas no Concílio Vaticano II e na grande tradição), a segunda parte propõe "Normas gerais" (baseadas no Direito Canônico, Art. 1, 1). Na primeira parte, por sua vez, há dois temas didaticamente distintos, embora indissociáveis: a Identidade (n. 12-29) e a Missão (n. 30 a 49). Trataremos, mais especificamente, da missão, na qual está inserida a atividade pastoral (n. 38-42), depois de fazer breve alusão à identidade que se postula em relação à missão "substantiva" de toda universidade.

\section{Identidade em relação}

"Nascida do coração da Igreja, a origem da universidade católica confundese com o próprio surgimento da universidade como tal" (JOÃO PAULO II, 1980, n. 1). Enquanto "universidade", 
a universidade católica é uma comunidade acadêmica que, de modo rigoroso e crítico, contribui para a defesa e o desenvolvimento da dignidade humana, como também para a herança cultural, mediante a investigação, o ensino e os diversos serviços prestados às comunidades locais, nacionais e internacionais (JOÃO PAULO II, 1980, n. 12).

Enquanto "católica", a universidade deve possuir as seguintes características: inspiração cristã dos indivíduos e de toda a comunidade; reflexão incessante sobre o tesouro crescente do conhecimento humano; fidelidade à mensagem cristã tal como é apresentada pela Igreja; empenho institucional para servir ao povo de Deus e à família humana na busca do sentido transcendente da vida (JOÃO PAULO II, 1980, n. 13).

No Brasil, país de povo religioso e Estado laico, dois aspectos principais surgem como desafios e oportunidades à identidade de uma universidade católica: primeiro, o conceito tripartite de toda universidade, cuja articulação de ensino, pesquisa e extensão tornou-se um diferencial de nossas UC; em segundo lugar, a natureza comunitária de nossas instituições, nem pública estatal nem privada particular, por mais desafiantes que sejam, coloca nossas universidades em uma situação de serviço às comunidades, bem como uma possibilidade de consolidação da própria comunidade universitária.

\section{Da Missão em geral, da pastoral em particular}

A missão fundamental de uma universidade é a procura contínua da verdade, a conservação e a comunicação do saber para o bem da sociedade. A universidade católica participa dessa missão com o contributo das características e finalidades específicas (JOÃO PAULO II, 1980, n. 30, destaque nosso).

De entrada, a definição da missão das universidades católicas é afirmada como "participação" da missão geral de toda universidade, visando ao bem da sociedade, mediante os saberes em sua universalidade. E dentro dessa missão "fundamental", a universidade católica marcará sua especificidade em quatro 
aspectos principais: serviço à Igreja e à Sociedade (n. 31-37); pastoral universitária (n. 38-42); diálogo com a cultura (n. 43-47) e evangelização (n. 4849).

Estruturalmente, a missão cristã é afirmada primeiramente como "serviço" à Igreja e à Sociedade, concluindo-se com um tema também amplo, a "evangelização". Mas, enquanto serviço e evangelização estão no horizonte amplo da missão, duas "atividades” (JOÃO PAULO II, 1980, n. 38, 43) figuram como específicas: a pastoral e o diálogo com a cultura. Enquanto a pastoral está mais voltada para a comunidade universitária ad intra (n. 38), o diálogo cultural é uma "ponte" da universidade com a sociedade e, igualmente, das ciências com "qualquer cultura" (n. 43), acentuando-se, portanto, a dimensão ad extra. Essa abertura é própria de "toda universidade", enquanto a universidade católica “participa desse processo oferecendo a rica experiência cultural da Igreja” (n. 43).

\section{Serviço à Igreja em Sociedade}

O serviço caracteriza, portanto, a missão substantiva da universidade católica em relação à Igreja e à Sociedade. Mais do que separar esses dois âmbitos, importa explicitá-los para melhor perceber o alcance e distinguir a relação diferenciada com uma e outra. Em relação à Igreja, o serviço prestado "mediante o ensino e a investigação" é uma contribuição "indispensável" porque "prepara homens e mulheres para assumir, em sua vocação cristã" e "lugares de responsabilidade na Igreja”, e também porque, graças aos resultados das investigações, “a universidade poderá ajudar a Igreja a responder aos problemas e exigências do tempo" (JOÃO PAULO II, 1980, n. 31).

Mas, como qualquer outra instituição, “a universidade católica está inserida na sociedade humana" (n. 32). Por um lado, "ela é um instrumento, cada vez mais eficaz, de progresso cultural, quer para os indivíduos quer para a sociedade" (n. 31); e, por outro, a universidade católica com a "autonomia institucional e 
liberdade acadêmica" (n. 37) que lhes são próprias, "deverá ter a coragem de proclamar verdades incômodas que não lisonjeiam a opinião pública”, mas são "necessárias para salvaguardar o autêntico bem da sociedade" (n. 32). Somente o princípio da autonomia permitirá à universidade exercitar a liberdade e coragem institucionais de proclamar "verdades incômodas", fazendo prevalecer os argumentos fundados em saberes sobre "opiniões" que não honram a busca honesta da verdade maior e não têm fundamento a não ser em visões preconceituosas, acríticas e contrárias ao Evangelho. Essa autonomia necessária, porém, não se confunde com uma mera "independência", da mesma forma que as verdades incômodas não são contraposição entre "doutrina" e "ciência". A rigor, tanto teremos que superar uma visão "doutrinária" da fé quanto teremos que criticar a ideologia positivista das ciências, de modo especial nas universidades brasileiras. Somente um discernimento mais agudo, tanto do tipo de autonomia quanto das verdades a proclamar, pode assegurar uma interpretação justa do que a Ex corde Ecclesiae indica como referência.

Nesse passo, as atividades de "investigação" - acrescentem-se também ensino e extensão, inseparáveis na concepção brasileira - devem incluir o "estudo dos graves problemas contemporâneos", tais como

a dignidade da vida humana, a promoção da justiça para todos, a qualidade da vida pessoal e familiar, a proteção da natureza, a procura da paz e da estabilidade política, a repartição mais equânime das riquezas do mundo e uma nova ordem econômica e política que sirva melhor à comunidade humana, em nível nacional e internacional (JOÃO PAULO II, 1980, n. 32).

Mais especificamente, caberá à universidade católica um "discernimento dos valores e das normas dominantes na sociedade e na cultura moderna”, assim como "a responsabilidade de comunicar à sociedade aqueles princípios éticos $\mathrm{e}$ religiosos que dão pleno significado à vida humana". Sabemos que a forma de comunicar é tão importante quanto a mensagem; por isso, importa atualizar 
linguagens e significações, com "fidelidade criativa" (CERTEAU, 1970, p. 128-136), para "dar razões de nossa esperança" (1 Pd 3,15s) para cada nova geração.

A "promoção da justiça social" - segundo o Evangelho e interpretado pela doutrina social da Igreja - e a "responsabilidade" da universidade católica segundo os limites de suas possibilidades - são destacados no âmbito da sociedade na qual está inserida, bem como na promoção de povos e nações em vias de desenvolvimento (JOÃO PAULO II, 1980, n. 34).

A universidade católica deve promover a "cooperação dos saberes" na busca de respostas a tantos problemas complexos e, igualmente, a "cooperação em projetos comuns de investigação", tanto em parceria com outras instituições públicas e privadas quanto por meio das redes nacionais e internacionais (n. 35), promovendo "a solidariedade na sociedade e no mundo" (n. 37). A menção feita à FIUC - Federação Internacional de Universidades Católicas - (n. 35) é uma bela oportunidade para recordar que a promoção da cooperação entre as universidades constitui o objetivo maior da Federação, segundo seus estatutos e o novo Plano Estratégico $^{8}$.

\section{Pastoral universitária como diálogo entre fé e vida}

A pastoral universitária é aquela atividade da universidade que oferece aos membros da própria comunidade a ocasião de coordenar o estudo acadêmico e as atividades para-acadêmicas, com os princípios religiosos e morais, integrando, assim, a vida com a fé (JOÃO PAULO II, 1980, n. 38).

Enquanto atividade integradora da vida acadêmica com a fé cristã, a pastoral realiza "a missão da Igreja na universidade", de forma específica e explícita (n. 38). Enquanto atividade de "coordenação", a pastoral colabora para que toda a comunidade universitária possa "encarnar a fé nas atividades cotidianas”, promovendo momentos de reflexão e oração, além da celebração dos

\footnotetext{
${ }^{8}$ Ver no site <www.fiuc.org $>$.
} 
sacramentos (n. 39). Por sua vez, cabe também à pastoral, promover o respeito que as comunidades acadêmicas devem salvaguardar daquelas pessoas que pertencem a outras igrejas ou religiões (n. 39).

Para além dos círculos da comunidade universitária, a pastoral deverá exortar professores e alunos a serem conscientes de sua responsabilidade em relação aos que mais sofrem física e espiritualmente (n. 40). Enfim, a atividade pastoral é indispensável e poderá contribuir para que os estudantes católicos estejam mais "preparados a participar ativamente na vida da Igreja” (n. 41), graças à competência profissional de qualidade e à formação profissional.

De certa forma, o documento é bastante discreto e até tímido em relação à atividade pastoral. Primeiro, porque a Ex corde Ecclesiae se situa, forçosamente, no horizonte internacional, supondo diversos contextos. Segundo, porque se trata de um documento de "referência" (n. 8), na perspectiva de uma orientação geral, deixando a cada universidade a criatividade de adaptação, conforme o seu próprio contexto social, eclesial, inter-religioso ou pertença a espiritualidades específicas (salesiana, marista, diocesana, jesuíta, etc.), expressando o rico patrimônio do catolicismo. Enfim, a Constituição Apostólica de João Paulo II não se fecha em um modelo de pastoral, abrindo o leque a experiências distintas e, portanto, suscitando a possibilidade de enriquecimentos de uns com as experiências de outros, em nome da uma catolicidade aberta ao sopro do Espírito: “em virtude dessa catolicidade cada uma das partes traz seus próprios dons as demais partes e a toda a Igreja” (CONCÍLIO VATICANO, 2., Lumen Gentium, 2010, 13,3).

\section{Diálogo com a cultura em sua pluralidade}

A universidade católica, por um lado, "participa” do processo de promoção da cultura, mediante o ensino ("transmissão às gerações sucessivas"), a pesquisa (“investigação") e a extensão ("iniciativas culturais e serviços educativos”), "aberta a toda experiência humana" e "disposta ao diálogo e aprendizagem de qualquer 
cultura"; por outro lado, postula que a cultura humana deve estar aberta à Revelação e à transcendência, tornando-se, assim, um lugar privilegiado para o diálogo entre o Evangelho e a cultura (JOÃO PAULO II, 1980, n. 43).

Nesse passo, a universidade católica "assiste à Igreja" tanto no melhor "conhecimento das diversas culturas" e discernimento de seus aspectos positivos e negativos, quanto na tarefa de tornar a fé mais compreensível a determinadas culturas. Pois, se é verdade que o Evangelho não se identifica com uma cultura particular, da mesma forma, as pessoas estão ligadas a uma cultura e os elementos culturais são indispensáveis à construção do Reino (n. 44).

Por sua vez, a universidade católica "deve tornar-se cada vez mais atenta às culturas do mundo de hoje" e consciente das "várias tradições culturais existentes na Igreja”, de maneira a promover um contínuo diálogo entre o Evangelho e a sociedade de hoje (n. 45), sobretudo em vista de discernir e avaliar as aspirações e contradições da cultura moderna (n. 45); defender as culturas tradicionais, ajudando-as a acolher os valores modernos, sem renunciar ao seu patrimônio (n. 45); promover o diálogo entre pensamento cristão e ciências modernas (n. 46); promover o diálogo ecumênico (horizonte da "unidade dos cristãos”) e o diálogo inter-religioso (horizonte do discernimento "dos valores espirituais presentes nas várias religiões”).

\section{Evangelização no coração do mundo}

A universidade católica participa da missão de evangelização da Igreja, a saber, "garantir a relação fé e vida", mediante o "anúncio da Boa-nova a todos os estratos da humanidade" e "transformar, a partir de dentro, tornando nova a própria humanidade" (n. 48). Cada universidade contribui com a Igreja nessa missão evangelizadora: primeiro, dando um testemunho vital e institucional em favor do Cristo diante do secularismo; segundo, porque todas as atividades de uma universidade católica estão harmonizadas com a missão evangelizadora da Igreja, de forma explícita ou implícita: “colocando as novas descobertas humanas a 
serviço dos indivíduos e da sociedade; a formação de pessoas capazes de discernimento crítico e conscientes da dignidade transcendente da pessoa humana; a formação profissional, ética e com senso de serviço ao outro; o diálogo com a cultura para melhor compreender a fé; a investigação teológica que ajuda a fé a exprimir-se em linguagem nova (n. 49). E, ao reler a carta magna das universidades católicas e, sobretudo, ao concluir com o tema da evangelização, importa reafirmar a centralidade do próprio Evangelho, no sentido paulino do termo 9 , traço que tem marcado o pontificado do Papa Francisco, em suas palavras e gestos (FRANCISCO, 2013; FREDERIC LENOIR, 2014).

Finalmente, esses quatro aspectos da missão universitária devem ser interpretados dentro de uma correlação, o que significa que eles são irredutíveis um ao outro e, ao mesmo tempo, complementares. Assim, por exemplo, não se pode identificar a missão da universidade apenas com a atividade pastoral, por mais importante e até indispensável (JOÃO PAULO II, 1980) que ela seja. Mas, por sua vez, cada aspecto da missão está atravessado pelo "princípio da pastoralidade" (THEOBALD, 2009), no sentido do concílio Vaticano II, a saber: fundada no modus agendi do próprio Cristo e de seus apóstolos (PAULO VI, 1965, n. 11), a "pastoralidade" é uma maneira de proceder que implica escutar a Palavra de Deus e, ao mesmo tempo, escutar-se mutuamente e perceber os acontecimentos do mundo; portanto, a escuta da Palavra de Deus não pode ser separada de um discernimento concomitante dos "sinais dos tempos"10.

\footnotetext{
9 “[...] força de Deus para a salvação de todo aquele que crê, em primeiro lugar do judeu, mas também do grego” (Rm 1, 16). Essa perspectiva encontra-se na própria Dei Verbum, 7: para superar a polêmica das duas fontes, Vaticano II resgatou a passagem do concílio de Trento sobre "a" (única) fonte. Portanto, Escrituras e Tradição não são duas fontes, mas, ambas estão referidas à única fonte, o Evangelho. Aspecto interessante a conferir a nota que se remete ao concílio tridentino.

${ }^{10}$ Ver palestra proferida na Universidade Católica de Pernambuco por Christoph Théobald, sob o título de "Vaticano II: do 'concílio pastoral' à pastoralidade conciliar".
} 


\section{À maneira de conclusão aberta}

Ao termo desse breve percurso, gostaria de concluir retomando alguns aspectos sob a forma de pistas de um discernimento e aprofundamento da missão das universidades católicas, sobretudo neste ano comemorativo: o cinquentenário do encerramento do Vaticano II, primeiro concílio a tratar, especificamente, da educação como missão da igreja em um documento e, igualmente, dos 25 anos da Ex corde Ecclesiae. Trata-se, porém, de remeter a esses documentos para lançar a tradição revisitada como uma âncora para o futuro $(\mathrm{Hb} 6,19)$.

1. Cinquenta anos depois do concílio, cumpre realizar uma tarefa hermenêutica de recepção, aprofundando a noção de discernimento da missão cristã no coração de uma cultura cada vez mais plural e de um mundo interconectado. Não basta, porém, identificar os "problemas" do tempo presente, mas interpretá-los à luz da Palavra de Deus, segundo a centralidade do Evangelho. Esse labor teológico supõe uma releitura dos textos conciliares em perspectiva crítica e intertextual, não apenas para perceber a comunicação entre um documento e outro, mas também as novas questões e as novas abordagens (QUEIRUGA, 2015). Enfim, para além dos conflitos de interpretação dos textos, cabe continuar o espírito dialogal, ecumênico e pastoral.

2. Considerando os 25 anos da Constituição Apostólica Ex corde Ecclesiae, em 2015, e o clima de esperança e expectativa de renovação que vive a nossa Igreja com o Papa Francisco, proponho às universidades católicas a releitura e aprofundamento desta "carta magna", tanto de forma avaliativa quanto prospectiva. Trata-se de repertoriar questões antigas e novas, surgidas a partir dos contextos de nossos países e das respostas dadas por nossas instituições nesses anos de recepção da ECE. Segundo P. Ricoeur, "interpretar é interpretar-se diante do texto", pois, mais que procurar um sentido que está "por trás do texto", importa encontrar o sentido que se desenvolve "diante do texto" (RICOEUR, 1969, p. 183- 
211). No caso, portanto, não se trata de "aplicar" a Constituição Apostólica ECE à realidade, mas, sobretudo, de tomá-la como "referência” (JOÃO PAULO II, 1980, n. 8), tanto para apropriar-se de seu espírito quanto para reescrever a "carta de princípios” ou o Plano de Ações de cada universidade, contribuindo, assim, para o enriquecimento do patrimônio universal das universidades católicas, em sua missão de "serviço à Igreja em sociedade".

3. Considerando a globalização e a mundialização, bem como o conjunto de valores emergentes, sobretudo veiculado pelas novas gerações de jovens estudantes, a universidade católica está chamada a discernir e reinterpretar a sua missão de "busca da verdade", não apenas sob o paradigma do conhecimento e do saber científico (BENTO XVI, 2006), mas incluindo as novas linguagens (problema de transmissão de valores), as novas formas de comunicação (SPADARO, 2012, 2013) e resgatando a visão sapiencial (presente nas Escrituras e em todas as culturas, da América latina à Austrália). Trata-se, enfim, de associar à missão da comunidade acadêmica, a dimensão estética ("a beleza salvará o mundo ${ }^{11}$ ”) e renovar o compromisso ético dos saberes e das profissões ("prioridade da ética sobre a técnica”) (JOÃO PAULO II, 1980, n. 18) e/ou repensar a relação entre tecnologia e ética).

4. Considerando a cultura contemporânea e alguns valores contrários ao Evangelho e ao bem da sociedade, “a universidade católica deverá ter a coragem de proclamar verdades incômodas”, dentre as quais proponho o discernimento crítico de três ideologias e suas metamorfoses: primeiro, o neoliberalismo generalizado, difundido em proporções mundiais; segundo, o secularismo, não somente em razão do laicismo reinante (secularização e laicidade), mas também da transformação do religioso

\footnotetext{
${ }^{11}$ Essa célebre frase de F. Dostoievski foi retomada pelos dois papas anteriores: Carta aos Artistas, de João Paulo II (1999) e Discurso de Bento XVI aos Artistas na Capela Sistina (2009). Bento XVI faz referência, inclusive, à Mensagem do papa Paulo VI aos artistas no encerramento do Concílio Vaticano II, cito: "Este mundo no qual vivemos precisa de beleza para não se precipitar no desespero. A beleza, como a verdade, é o que infunde alegria no coração dos homens [...]. Recordai-vos que sois os guardiões da beleza do mundo" (Ibid.).
} 
em produto de mercado (reificação do sagrado); terceiro, o relativismo, nem sempre de forma consciente e crítica, mas crescente no terreno prático.

5. Considerando o agiornamento iniciado com o Concílio Vaticano II e, ao mesmo tempo, a rapidez das mudanças e a falta de referenciais das jovens gerações (BARBOSA, 2012), a universidade católica precisa repensar a sua proposta pastoral. Somente um estudo aprofundado do "princípio conciliar da pastoralidade", baseado na escuta da Palavra de Deus e no discernimento dos sinais dos tempos, será capaz de propor uma pastoral universitária pertinente e inovadora, menos baseada em "atividades" pontuais (por mais importantes que elas sejam e sem excluílas) e mais orientada para uma "mística12" da experiência de Deus ${ }^{13}$. Nesse sentido, não basta fazer da pastoral universitária "uma atividade entre outras", nem é suficiente "adaptar" ao mundo universitário algumas formas e atividades pastorais próprias das paróquias ou dos movimentos. Também não podemos nos contentar com um recrutamento de jovens universitários para trabalhos sociais, movimentos espirituais e grupos de convivência. Sem excluir, necessariamente, esses "meios", a pastoral universitária deve contribuir de forma diferenciada e complementar na missão da Igreja, ousando discernir os maiores apelos de Deus nos acontecimentos, exigências e aspirações das jovens gerações.

6. Considerando a grande tradição do humanismo cristão e, nos tempos atuais, a pluralidade das sociedades, os anseios das gerações jovens e as novas sensibilidades diante de situações humanas diversas, a necessidade de propor novos humanismos. Que cada universidade católica possa contribuir nessa tarefa tão difícil quão necessária de dialogar com as mais diferentes tendências em vista de colaborar na

\footnotetext{
12 "O cristão do futuro ou será um místico ou já não será cristão": sentença de K. Rahner, traduzida e tematizada por Libanio (2002, p. 21).

${ }^{13}$ Sobre a diferença entre experiência religiosa e experiência de Deus, ver o magistral artigo de Henrique Cláudio de Lima Vaz (1998, p. 241-256).
} 
elaboração de um novo humanismo; inspirado do cristianismo, claro, mas aberto a "todas as nações", considerando a contribuição de uma diversidade de formas de pensar, viver e crer.

7. Em tempos de pós-modernidade e mundo globalizado, diante dos "escombros da cristandade e da modernidade", a universidade católica não pode deixar de buscar e propor as razões de nossa esperança. A esperança da fé, porém, não é pura utopia, nem sonho irreal, nem projeto unicamente humano; é uma esperança "razoável e sustentável", sinal de uma promessa messiânica e escatológica, anunciando o "fim do mundo", tanto no sentido do desmoronamento de todo sistema de totalidade quanto do anúncio de um novo mundo possível. Afinal, "esperança não é esperar, mas caminhar (ROCHA, 2010, p. 113-134)": desde o primeiro passo de Abraão ao último ato de todo aquele que não se desespera nunca, mas, caminhando, espera em Deus "contra toda esperança" (Rm 4,18).

Nesse caminho da esperança abraâmica, enfim, o ser humano não caminha sem destino nem está sozinho, mas conta com a presença fiel de Deus que se manifestou ao longo da história: depois da promessa feita à Abraão, pai da fé, ele se fez presente pelos profetas, visitou a humanidade na pessoa de seu filho Jesus Cristo e selou sua presença definitiva no meio de nós com um Novo Paráclito, o Espírito vivificador, como promessa sem fim. Nesse passo, as universidades católicas também não estão sozinhas em sua missão: elas participam da mesma missão de busca da verdade de toda universidade e de tantas outras instituições, grupos e pessoas de boa vontade; ao mesmo tempo, elas têm a missão privilegiada de "unificar existencialmente, no trabalho intelectual, duas ordens de realidade que, não raro, tendem a opor-se, como se fossem antitéticas: a investigação da verdade e a certeza de conhecer, já, a fonte da verdade" (JOÃO PAULO II, 1980, n. 1). Nenhum "adepto do caminho" está sozinho porque, no próprio ato de envio em missão (“ide”, Mt 28,19), recebemos a promessa do Ressuscitado estar no 
meio de nós "todos os dias até a consumação dos séculos" (Mt 28,20). E dessa promessa, as universidades católicas são destinatárias, testemunhas e discípulas!

\section{REFERÊNCIAS}

BARBOSA, Lívia (org.). Juventudes e gerações no Brasil Contemporâneo. Porto Alegre: Editora Sulina, 2012.

BENTO XVI. Discurso do Papa Bento XVI por ocasião do encontro com os artistas na capela sistina. 21 nov 2009. Disponível em: <https://goo.gl/WP21mB $>$. Acesso em: jul. 2015.

BENTO XVI. Discurso del Santo Padre en la Universidad de Ratisbona:Fe, razón y universidad. Recuerdos y reflexiones. 12 set. 2006. Disponível em:

<https://goo.gl/640C98>. Aceso em: jul. 2015

CONSELHO EPISCOPAL LATINO-AMERICANO (CELAM). Documento de Aparecida: Texto conclusivo da V Conferência Geral do Episcopado Latino-Americano e do Caribe, n. 342. São Paulo: Paulus; Paulinas;CNBB, 2009.

CERTEAU, Michel de. Les structures de communion à Boquen. Études, Paris, t. 332, jan., p. 128-136, 1970.

CIRNE, Lúcio Flávio R. O espaço da coexistência. Uma visão interdisciplinar de ética socioambiental. São Paulo/Recife: Ed. Loyola/Unicap, 2013.

CONCÍLIO VATICANO, 2. Lumen gentium: Constituição dogmática sobre a Igreja. 22. ed. São Paulo: Paulinas, 2010. 142 p.

CONCÍlIO VATICANO, 2. Gaudium et spes: Constituição Pastoral do Concílio Vaticano II sobre a igreja no mundo de hoje. 16. ed. São Paulo: Paulinas, 2009. 138 p. (A voz do Papa ; 41)

FRANCISCO, Papa. Evangelli Gaudium. A alegria do Evangelho: sobre o anúncio do Evangelho no mundo atual. São Paulo: Loyola, Paulus, 2013.

FRANCISCO, Papa. Laudato Sí. Encíclica sobre o cuidado da casa comum. São Paulo: Paulus, Loyola, 2015.

FREDERIC LENOIR, François. Le printemps de l'Évangile. Paris: Fayard, 2014.

GAUCHET, Marcel. Désenchantement du monde. Paris : Gallimard, 1985.

GAUCHET, Marcel. Un monde désenchanté? Paris: Les Éditions de l’Atelier, 2004. 
HERVIEU-LEGER, Danièlle. Le pèlerin et le converti: la religion en mouvement. Paris: Flammarion, 1999.

HERVIEU-LEGER, Danièlle. Vers un nouveau christianisme? Paris: Cerf, 1987.

JOÃO PAULO II, Papa. Ex corde Ecclesiae: Constituição Apostólica sobre as Universidades Católicas. 1980. Disponível em: <http://goo.gl/ZZa3dy>. Acesso em: ago. 2015 .

JOÃO PAUlO II, Papa. Carta do Papa João Paulo II aos artistas. 04 abr. 1999. Disponível em: <https://goo.gl/LdEXMx>. Acesso em: ago. 2015.

LIBANIO, João Batista. A religião no início do milênio. São Paulo: Loyola, 2002.

MENDOZA-ÁlVAREZ, Carlos. O Deus escondido na pós-modernidade. São Paulo: É Realizações Editora, 2011.

METZ, J. B. La foi dans l'histoire et dans la société. Essai de théologie fondamentale pratique. Paris: Cerf, 1999.

MORIN, E. Os sete saberes necessários à educação do futuro. São Paulo/Brasília:Cortez/ Unesco, 2000.

PAULO VI, Papa. Dignitatis Humanae: Declaração sobre a liberdade religiosa. 11: A liberdade religiosa está de acordo com o comportamento de Cristo e dos Apóstolos. 1965. Disponível em: <http://goo.gl/ABlCP5>. Acesso em: jul. 2015.

QUEIRUGA, A. T. A teologia depois do Vaticano II. Diagnóstico e propostas. São Paulo: Paulinas, 2015.

RICOEUR, P. Du texte à l'action. Paris: Seuil, 1969. p. 183-211.

ROCHA, Zeferino. Esperança não é esperar, é caminhar. Reflexões filosóficas sobre a esperança e suas ressonâncias na teoria e na clínica psicanalítica. In. ROCHA, Z. Freud entre Apolo e Dionísio: recortes filosóficos, ressonâncias psicanalíticas. São Paulo/ Recife: Edições Loyola/UNICAP, 2010. p. 113-134.

SPADARO, A. Ciberteologia. Pensar o cristianismo nos tempos da rede. São Paulo: Paulinas, 2012.

SPADARO, A. Web 2.o Redes Sociais. São Paulo: Paulinas, 2013.

TEIXEIRA, Faustino; MENEZES, Renata (org.). As religiões no Brasil: Continuidades e rupturas. Petrópolis: Vozes, 2006.

THEOBALD, Christoph. La réception du concilie Vatican II. 1. Accéder à la source. Paris: Cerf, 2009. 
THEOBALD, Christoph. "Vaticano II: do Concílio pastoral à pastoralidade conciliar hoje". In: CONFERENNCIA COM O PROFESSOR CHRISTOPH THEOBALD, DO CENTRO

SÈVRES, PARIS, 2012, Paris, França. Disponível em: <http://unicapcursodeteologia.blogspot.com.br/2012/10>.

VAZ, Henrique Cláudio de Lima. A linguagem da experiência de Deus. In: VAZ, H. C. L. Escritos de filosofia I: Problemas de fronteiras. São Paulo: Loyola, 1998, p. 241-256. 